\title{
O INSÓLITO NOS CORDÉIS DE FRANKLIN MAXADO
}

\author{
Calila das Mercês Oliveira ${ }^{1}$ \\ Raquel Machado Galvão ${ }^{2}$ \\ Roberto Henrique Seidel ${ }^{3}$
}

\begin{abstract}
Resumo: O insólito nos cordéis de Franklin Maxadopropõe uma análise acerca de quatro livretos de cordel do escritor e poeta baiano Franklin Maxado, discutindo quadros do elemento insólito recorrentes nos cordéis, aqui entendidos por fatos extraordinários, não habituais à realidade. Valorizada por alguns estudiosos como a raiz da cultura luso-brasileira, ou da cultura popular, a literatura de cordel herda características da literatura oral dos antigos trovadores. Os livretos artesanais, por vezes acompanhados de xilogravuras, foram distribuídos, inicialmente, em feiras livres, e tiveram em Feira de Santana, cidade do agreste da Bahia onde Franklin nasceu, um importante ponto de distribuição. É recorrente na literatura de cordel a utilização de narrações ritmadas e originais que abarcam o fantástico e o maravilhoso. Isto pode ser verificado neste estudo. As teorias presentes no artigo se baseiam em Tzvetan Torodov, Italo Calvino, Câmara Cascudo, Remo Ceserani, IrlemarChiampi, entre outros.
\end{abstract}

Palavras-Chave: Agreste, Franklin Maxado, Insólito, Literatura de cordel, Sertão.

Abstract: The unusual in popular literature's books by Franklin Maxado proposes a review about four booklets of the writer of Bahia and poet Franklin Maxado, discussing about the unusual frames that happen en books of the popular culture. We understand unusual like extraordinary facts, that doesn't happen in reality. Prized by some researchers as the root of the Luso- Brazilian culture, or popular culture, popular literature brings characteristics

Mestranda do Programa de Pós-Graduação em Estudos Literários (PROGEL) da Universidade Estadual de Feira de Santana (UEFS); integrante do grupo de pesquisa "Publicações na Bahia: mapeamento e diagnóstico das editoras baianas"; bolsista de Extensão do CNPq (EXP-C). Endereço eletrônico: caliladasmerces@gmail.com.

Mestranda do PROGEL/UEFS; integrante do grupo de pesquisa "Publicações na Bahia: mapeamento e diagnóstico das editoras baianas"; bolsista CAPES. Endereço eletrônico: raquelgcultura@gmail.com.

3 Professor Titular de Teoria da Literatura junto ao Dep. de Letras e Artes e PROGEL/UEFS; líder do grupo de pesquisa financiado pelo CNPq "Publicações na Bahia: mapeamento e diagnóstico das editoras baianas", chamada n. 80/2013 CNPq/SEC/MinC; integrante do grupo de pesquisa da ANPOLL "Vertentes do insólito ficcional". Endereço eletrônico: r.h.seidel@gmail.com. 
of oral literature, of the ancient troubadour poets. The handmade booklets, sometimes accompanied by woodcuts were distributed initially in free markets, and had in Feira de Santana, city of Bahia where Franklin was born, one important point of distribution. The stories are unique and rhythmic and show aspects of the fantastic and the wonderful. This can be verified in this study. Theories present in the article are based on Tzvetan Torodov, Italo Calvino, Cascudo, Remo Ceserani, Irlemar Chiampi, among others.

Keywords: Agreste, Franklin Maxado, Unusual, Cordel literature; Sertão.

\section{INTRODUÇÃO}

Cordel: poesia ritmada fundida no sertão que faz parte da literatura popular. Arte que mistura gráfica, canto, artes plásticas, jornalismo, teatro, poesia, comércio e temáticas variadas. O cordel ao mesmo tempo que é marginal é tão grandioso, pois serviu/serve de suporte inspirador para outras criações artísticas como cinematográficas, musicais, teatrais, plásticas e até mesmo literárias de outros gêneros.

A literatura de cordel ${ }^{4}$, característica da cultura popular, embora não canônica, engloba muitos aspectos e inesgotáveis assuntos para serem pesquisados. E debruçar um estudo sobre a cultura popular só se tornou possível a partir dos estudos culturais, que seriam encabeçados pelos "politeístas literários", segundo o ensaísta e professor Sérgio Medeiros (1998, p. 45):

No que se refere aos politeístas, gostaria de mencionar que, entre outras posturas moderadas e extremadas, adotam às vezes atitudes que podem espantar o estudante incauto. A dos pós-ocidentalistas, por exemplo, que são teóricos e críticos que não estão mais preocupados com a densidade das produções artísticas, mas com a diversidade da enunciação: voz dos excluídos e das minorias.

Esse trabalho sobre literatura de cordel carrega uma diversidade de pontos de partida, característicos também desse politeísmo possível que já foi citado anteriormente. O primeiro é a cidade de Feira de Santana, um dos

${ }^{4}$ O surgimento da literatura de cordel detém diferentes hipóteses. Em algumas referên- cias, dizem que sua origem foi século XVI na Península Ibérica, os folhetos de cordel e- ram chamados de "pliegos sueltos" (Espanha) e "folhas soltas" ou "volantes" (Portugal). O fato é que a ascensão da imprensa pós-Gutemberg possibilitou a publicação dessa lite- ratura que conservou características da narração oral, da memória dos antigos trovado- res em verso e prosa. Das terras do além mar, onde os impressos eram vendidos através da exibição em barbantes ou cordão, que em língua galega é cordel, ele chegou ao Brasil.

Número temático: Vertentes do insólito nas literaturas das Américas. A Cor das Letras - 
municípios mais conhecidos do interior baiano. A segunda cidade mais populosa do estado se situa a $108 \mathrm{~km}$ da capital, Salvador, e possui identidade típica do agreste. Cidade centenária, elevada à condição em 1873, conhecida também como Portal do Sertão, Feira de Santana tem uma população de mais de 600 mil pessoas e uma considerável tradição econômica e cultural.

Desde o começo do século passado, a literatura sempre esteve presente no município e o gênero cordel tem sido representado por inúmeros escritores na região, como Cuíca de Santo Amaro (José Gomes), João Crispim Ramos, Dadinho, Vado Di Namite, o sergipano Antonio Silva, Asa Filho e Franklin Maxado. De feira em feira, os poetas e vendedores de cordel comercializavam as publicações impressas, tendo como suporte a declamação. Na década de 1970, várias pessoas se reuniam na feira popular no centro de Feira de Santana. Era o ponto de encontro de moradores, viajantes e forasteiros e foi lá que os primeiros folheteiros começaram a aparecer com livretos contando histórias de bravura e aventura.

Ligada ao cotidiano de pessoas "comuns" e às tradicionais maneiras de contar histórias de forma oral e criativa para o povo sertanejo, o pesquisador e estudioso da cultura popular brasileira Câmara Cascudo (1898-1986) afirma que no gênero secular "floresceram, noutra indumentária, as tradições seculares" (1968, p. 22). Assim, o cordel firmou-se na dinâmica do povo do nordeste como um aspecto vivenciado e um sentimento acoplado ao cotidiano e à vida deles. Diegues Junior $(1977$, p. 3) relata que "nas naus colonizadoras, com os lavradores, os artíficies, a gente do povo, veio naturalmente a tradição do Romanceiro, que se fixaria no Nordeste do Brasil, como literatura de cordel".

Partindo desse recorte literário, vamos tratar da representação do insólito em uma literatura marcada pela marginalidade, justamente por carregar características da oralidade e ser realizada muitas vezes por escritores que estão à margem ou como minoria em um sistema literário alicerçado pelo capital. Quando estamos falando de representação no sentido de recorte ou retrato de uma determinada sociedade, podemos resgatar a questão das múltiplas e amplas formas de representação dentro da literatura, como levanta Hanna Pitkin (2006, p. 16):

O conceito de representação é um caso instrutivo porque seu significado é altamente complexo e, desde muito cedo na história dessa família de palavras, tem sido altamente abstrato. A representação é, em grande medida, um fenômeno cultural e político, um fenômeno humano. 
Para a estudiosa, representar é uma atividade humana, mas não um agir para o outro. Quem representa figura, pinta e encena. Aplicada ao caso do cordel, a representação das histórias, sejam elas com uma forte ou menor ligação com os fatos do cotidiano, é um fenômeno híbrido entre a militância cultural e social e a necessidade de expor acontecimentos reais, surreais ou causos imaginários.

\section{REVISÕES SOBRE O INSÓLITO}

O caráter insólito é uma característica recorrente na literatura de cordel. Embora tenha sido escrito no século passado, não podemos desconsiderar quando o filósofo e linguista, pioneiro nos estudos sobre aspectos do fantástico, Tzvetan Todorov (1939), em Introdução a literatura fa $n$ - tbstica, afirma que hesitação do leitor é uma marca do que diz respeito ao gênero fantástico, sendo esta, uma condição primordial para que ele exista. Todorov ainda subdivide o gênero, a depender da resposta do leitor e/ou protagonista:

Vimos que o fantástico não dura mais que o tempo de uma vacilação: vacilação comum ao leitor e ao personagem, que devem decidir se o que percebem provém ou não da "realidade", tal como existe para a opinião corrente. [...] Se, pelo contrário, decide que é necessário admitir novas leis da natureza mediante as quais o fenômeno pode ser explicado, entramos no gênero do maravilhoso (TODOROV, 1992, p. 24).

Sobre o insólito, a ideia de uma definição ainda é discutível. No artigo O "insólito" na narrativa ficcional : a questão e os conceitos na teoria dos gêneros literários, o pesquisador Flávio García aborda questões relativas à delimitação do gênero. Para García (2007), "é lícito opor o insólito ao nat ural e ao ordinário, termos comuns na teoria dos gêneros literários quando se quer falar de Maravilhoso, Fantástico, Estranho, Sobrenatural, Realismo Maravilhoso, Absurdo".

Assim, diante de uma rede de nomenclaturas e divisões, pode-se abarcar o insólito como algo sobrenatural aos olhos do senso comum, que assusta, surpreende, estagna e coloca o leitor em um papel de adepto a uma ficção mais "surrealista" do que "realista". No que tange à divisão den- tro do que se ousa chamar de insólito, a estudiosa IrlemarChiampi foi uma das percussoras do uso do termo Maravilhoso, ao diferenciá-lo do fantásti- co puro. No livro $O$ realismo maravilhoso, Chiampi afirma que o leitor tende 
a aceitar os eventos insólitos como parte do relato, sem problematizar sobre sua natureza extraordinária:

\begin{abstract}
Os objetos, seres ou eventos que no fantástico exigem a projeção lúdica de duas probabilidades externas e inatingiveis de explicação, são no realismo maravilhoso destituíd os de mistério , não duvidosos quanto ao universo de sentido a que pertencem . Isto é , possuem probabilidade interna , tfm causalidade no próprio âmbito da diegese e não apelam , portanto, à atividade de deciframento do leitor (CHIAMPI, 1980, p. 59).
\end{abstract}

O maravilhoso é uma criação que tem o leitor como comparsa. Geralmente, ele não questiona a ambientação da narrativa que mesmo fugindo dos moldes de mundo tradicionais, apenas acontece sem julgamentos. É observado que os aspectos do insólito têm sido amplamente discutido no Brasil e tem-se percebido a riqueza de novas teorias que convergem e se completam, não sendo rígida a necessidade do uso de apenas uma delas.

\title{
2 MAXADO NORDESTINO E OS ELEMENTOS INSÓLITOS NO CORDEL
}

Franklin de Cerqueira Barreiros Machado (1943), mais conhecido como Franklin Maxado ${ }^{5}$, nasceu em Feira de Santana e viveu maior parte da vida como poeta de literatura de cordel. Hoje tem mais de 400 folhetos de cordel publicados, com diversidade de estilos e temáticas, como cordéis infantis, humorísticos, eróticos, críticos, de causos, dramáticos, entre outros. Bacharel em Direito pela Universidade Católica de Salvador e em Jornalismo pela Universidade Federal da Bahia, Franklin Maxado foi influenciado pelos cantadores e vendedores de cordel que frequentavam a feira livre de Feira de Santana e tornou-se também uma referência no gênero, entre outros fatores pela circulação da sua obra na área literária e pela sua constante produção de cordéis.

Nos anos 1970, Franklin Maxado foi com destino a São Paulo a fim de divulgar o seu trabalho e lá viveu como artista popular e poeta de cordel, até mesmo no período da ditadura. $O$ escritor desenvolveu também outra arte, a xilogravura. Na Praça da República, começou a vender cordel com outros profissionais nordestinos. O trabalho apesar de itinerante lhe rendeu

5 O nome "Maxado" grafado com " $x$ " e utilizado preferencialmente pelo poeta desde os anos 1970, quando ele, também conhecido como Maxado Nordestino vivia na grande São Paulo e assinava assim nos folhetos e nas xilogravuras para referenciar a sua origem. 
certo reconhecimento, tendo publicado livros em uma das maiores editoras de cordel do país, a Luzeiro ${ }^{6}$.

No começo da década de 1980, Franklin Maxado retornou à Bahia e foi contratado para trabalhar da TV Educativa, fazendo intervenções com notícias em cordel. Ao voltar para a cidade natal, dirigiu os museus da Universidade Estadual de Feira de Santana (UEFS), o Museu Regional de Arte e o por ele idealizado, Museu Casa do Sertão. O poeta, atualmente, apresen- ta palestras em escolas e universidades e participa de bienais e feiras literá- rias dentro no Brasil. Maxado também realiza estudos de abrangência teó- rica e analítica sobre o gênero cordel, como verificado nos livros de própria autoria, Cordel (2007) e O que é cordel na literatura popular (2012).

O cordel está no hall dos gêneros literários considerados inclassificáveis. Existem tentativas de caracterizar as diferentes abordagens, porém nenhuma delas é consensual e é observável uma variedade de propostas neste quesito. No livro $O$ que é cordel na literatura popular, o poeta fala sobre as classificações propostas para os tipos de cordel que leva em conta a maioria do conteúdo do folheto e o traço estilístico do autor:

Assim, temos os folhetos de época ou de ocasião; históricos; didáticos ou
educativos; biográficos; de propaganda política ou comercial; de louvor ou
homenagem; de safadeza ou putaria; maliciosos ou de cachorrada; cômicos ou
de gracejos; de bichos ou infantis; religiosos ou místicos; de profecias ou eras;
de filosofia; de conselhos ou de exemplos; de fenômenos ou de casos;
maravilhosos ou mágicos; fantásticos ou sobrenaturais; de amor ou de
romance amoroso; de bravura ou heroicos; vaquejadas; de presepadas ou dos
anti-heróis; de pelejas ou de desafios; de discussão ou de encontros; de lendas
ou mitos; pasquim ou de intriga; etc. (MAXADO, 2012, p. 65).

Analisando de forma mais enfática aspectos da temática proposta pelo cordelista e deixando em segundo plano questões relativas à sintaxe, rima ou métrica, podemos encontrar uma grande diversidade de cordéis que abordam o aspecto maravilhoso. Essa tipologia engloba temas onde entram fadas, sereias, feiticeiras, monstros, fantasmas, dragões, gênios, deuses, almas, orixás, diabos, ogros e outros seres mágicos:

Os poetas versam sobre enredos que podem ser reais, entretanto, para atingir os fins, o herói encontra coisas ou seres irreais (maravilhosos) para auxiliá-lo, vendo outros artifícios (também fora do real) dos seus inimigos maus (MAXADO, 2012, p. 89).

6 A Editora Luzeiro (antiga Prelúdio) é uma gráfica de São Paulo voltada para o exercício da folheteria. Publica livros clássicos em formato de cordel.

32 Número temático: Vertentes do insólito nas literaturas das Américas. A Cor das Letras UEFS, n. 15, 2014 
Sobre o fantástico ou sobrenatural, Franklin Maxado ressalta que Ariano Suassuna (1927) foi o primeiro a diferenciar esse ciclo fantástico do maravilhoso. Nele, o poeta cria seu próprio mundo, os seus marcos inquestionáveis: "O fantástico é um mundo totalmente criado pelo poeta, onde ele dá asas à imaginação, mostrando exercício mental como se mostrasse valentia" (MAXADO, 2012, p. 91).

Maxado apresenta cordéis com temáticas variadas nos quais traz o insólito com características do fantástico e do maravilhoso. Podemos percebê-las em livretos como O Santo Jumento no Reino dos Céus (s/d), O casamento do lobisomem com uma vampira feiticeira (s/d), Saci e o Bicho Folharaz no reino da bicharada (2011) e A lenda da lara é a mesma de lemanjá e das sereias (s/d), selecionados para este estudo.

O poeta Franklin Maxado utilizou em suas obras personagens folclóricos e mitológicos que podem se enquadrar no fantástico, como no cordel $O$ Santo Jumento no Reino dos Céus, que fala da saga de um jumento, ani-mal doméstico de carga típico do sertão, depois da morte e elevado a santo beato. Personagens do cenário católico cristão, como Frei Damião, São Pedro, São João, Jesus, São Roque, São Francisco, São Benedito, Santo Antônio, São Cristóvão, São Jorge, São Expedito, "diversas Nossas Senhoras" (s/d, p. 3) dialogam entre eles e também com o "Santo Jumento" ao saber da possibilidade do animal ficar no céu junto a eles, criando uma divergên- cia entre outros santos, como São Cristóvão que tinha receio de perder a sua função, o seu espaço. A história exibe sentimentos de seres humanos no jumento, além de ações como cantar, rezar e discursar.

A transformação de um jumento em santo tem aspecto cômico sem perder as características do fantástico, uma vez que o espaço e ações são imaginados e criados nessa proposta de cordel. O cordelista cria um céu muito parecido com um nordeste, retratando santos da igreja católica no processo de aceitação do fato do jumento também ser um santo, o que não deixa de ser uma crítica social ao ser empregada a ironia. Ao final da saga, após a aceitação do "Santo Jumento" acontece uma festa no céu e começa a chover vinho na terra, outro fato extraordinário:

Acharam ser nosso mundo
Que estava se acabando
Pois chovia gelo roxo.
Se viu menino chorando.
Se viu mulher já parindo
E loucos até sorrindo.
Os casais se abraçando (s/d, p. 8). 
Maxado em vários livretos utiliza a figura do "Santo Jumento", um marco seu, que aborda questões religiosas mescladas a personalidades nordestinas. No livreto $O$ Casamento do Lobisomem com uma Vampira Feiticeira, por sua vez, pode-se ver um exemplo de cordel com aspectos do insólito fantástico e maravilhoso. Ele envolve seres extraordinários e místicos de histórias de terror no sertão:

Pois, é um caso de horror
Acontecido no sertão
Quando um desses lobisomens
Fez a sua união
Com uma vampira bruxa
Que bebia sangue pagão (s/d, p. 1).

O enredo trata de quando os dois seres excêntricos, o lobisomem e a vampira, firmaram um compromisso nas terras de Vila de Ventura e de como eles juntos conseguiram aterrorizar o cotidiano de uma cidade serta-neja, ao se transformarem em morcegos que atacavam as pessoas à noite. Durante a trama o autor revela as pessoas que estavam por trás dos "mons- tros" sugadores de sangue, Tião Mendonça, o coveiro conhecido como "Mão de Onça", e Ana Barata, a parteira conhecida como "Barata Descas- cada". Os dois descobriram a identidade secreta um do outro e resolveram se casar:

Marcaram o matrimônio

Pra noite de sexta-feira,

Dia 13 de agosto

Debaixo de uma jaqueira.

Por coincidência, era

Lua cheia altaneira (s/d, p. 7).

Tanto a vampira quanto o lobisomem são dois seres do imaginário popular cujas lendas de origem variam de acordo com a cultura local. Existem diferentes versões sobre os seus surgimentos, mas o que os coloca em confluência é a característica vilã, destruidora, noturna, metamórfica e misteriosa. Nessa união, esses dois seres sobrenaturais se fazem presentes em um cordel descritivo, mítico e fabuloso.

Remo Ceserani (1933), em O fantástico, discute alguns sistemas recorrentes na literatura fantástica, abordando uma atmosfera que envolve o quadro dessa narração: "a noite, a escuridão, o mundo obscuro" denotam a "preferência do fantástico pelos mundos tenebrosos, subterrâneos, do alem, 'subnaturais' mais do que 'sobrenaturais'” (2006, p. 77-79). 
Franklin Maxado também costuma agregar em suas histórias um teor de comicidade através de anedotas e causos que são baseados na história oral e popular. Em Saci e o Bicho Folharaz no reino da bicharada, o autor apresenta a história para o público infanto-juvenil com características da fábula, "No tempo em que os bichos / Falavam igual ao homem" (2011, p. 3), em que a narrativa envolve animais falantes e uma suposta moral da história:

\author{
Dona onça conformada \\ Respondeu que pagaria. \\ Queria saber apenas Como \\ era que bebia Porque só \\ tinha uma fonte $\mathrm{Na}$ qual \\ era vigia. \\ Explicou dona raposa \\ O que o Saci lhe ensinou. \\ Passar mel pelo corpo, \\ E depois se espojou, Em \\ uma ruma de folhas \\ Que no seu couro grudou. \\ Raposa não tinha força Pra \\ lutar com a maioral, Por \\ isso usou a astúcia, \\ Porque quem não é o tal \\ Maior tem que ser melhor \\ E assim não se dar mal (2011, p. 9).
}

A história conta a aposta feita pela onça e a raposa, dois animais selvagens que representam força e esperteza, respectivamente, no reino animal. Ambas fizeram uma aposta: a onça garantiu que no verão conseguiria pegar a raposa e, caso não acontecesse, a raposa exigia uma festa bancada pela onça para todos os animais da floresta. No final da narrativa, a onça não conseguiu pegar a raposa, pois a última se travestiu de um bicho dife-rente coberto por folhas, o Bicho Folharaz, atrapalhando os planos da onça. Desta forma, a onça perdeu a aposta e como combinado bancou a festa para toda a bicharada. Por fim, as duas prometeram se respeitar e se torna- ram amigas.

No texto há elementos do maravilhoso e do fantástico, como animais que agiam como humanos (falavam, dançavam, cantavam, tocavam tango e bolero, sambavam, etc.) e a presença de personagens folclóricos brasileiros, como o saci e a caipora. 
Em A lenda da lara é a mesma de lemanjá e das sereias ${ }^{7}$, a história tem forte apelo ao folclore brasileiro por contar a lenda da sereia lara, "Que seduzia os homens / Com seus cantos feiticeiros" (s/d, p. 1) e faz referência à mitologia grega, quando ratifica que a história "É a mesma de europeus / Com sereias perigosas" (s/d, p. 1) que atraiam os marujos para as águas e também faz correlação com os orixás lemanjá e Oxum, ambas "deusas africanas", do mar e do rio, respectivamente.

Todas elas são sereias Que
só mostram a cintura
Busto, pescoço e seios,
Seduzindo a criatura
Com canto, olhar, sorriso,
Convidando à ventura (s/d, p. 2).

No livreto, ele traz referências de aspectos do maravilhoso, como figuras religiosas e míticas, a exemplo de Deus, Nossa Senhora dos Navegantes e da Conceição, Oxum, lemanjá, e outros elementos que fazem parte do folclore como a sereia lara, a sereia dos europeus, Odin, entre outras de diferentes povos. E ainda aborda o sincretismo religioso existente no Brasil. Este estudo sobre os livretos de Franklin Maxado confirmam que o insólito está também associado ao gênero cordel. Evidentemente, que não somente nos cordéis de Maxado, mas é possível observar este aspecto que tange ao maravilhoso e ao fantástico em outros autores nordestinos que utilizam personagens similares, transitando neste mundo pitoresco e criado pelo imaginário do povo.

\section{REFLEXÕES E CONSIDERAÇÕES FINAIS}

Diante do grandioso acervo do escritor feirense, que aborda temas variados em seus folhetos, realizamos um recorte inédito focando o insólito nos cordéis O Santo Jumento no Reino dos Céus, O casamento do lobiso- mem com uma vampira feiticeira, Saci e o Bicho Folharaz no reino da bicha-rada e A lenda da lara é a mesma de lemanjá e das sereias. Pela evidência da presença de aspectos fantástico e maravilhoso, principalmente, tanto no enredo como no perfil de alguns dos personagens destas histórias, concluímos que as questões do insólito estão embutidas de forma intrínseca nas narrativas do povo do agreste baiano.

7 Maxado ilustra a capa com uma de suas xilogravuras. 
Ficou evidente também na pesquisa que na cidade de Feira de Santana ainda persiste um histórico movimento de cordel. A dinâmica continua sendo a mesma do final do século passado: venda de cordel em bancas de feiras livres ou até em feiras literárias que ocorrem esporadicamente na região. Imerso nesse mercado alternativo, composto por profissionais liberais das letras, como Franklin Machado, um agente literário da resistência dessa literatura que, embora marginal, permaneceu viva ao longo dos anos. Algo interessante para reflexão é observar a dificuldade dos cordelistas baianos em lidar com a impressão e distribuição dos livretos. Nesta área é comum que os próprios poetas cuidem da produção e distribuição do seu material.

Mesmo a considerar que na teoria todo processo produtivo é menos complicado que na prática e que quase todo escritor, seja de cordel ou não, abordando um insólito ou não, no Brasil contemporâneo sempre está no papel de resistência, o estudo propõe esse recorte estimulante sobre as representações da Literatura de Cordel em uma cidade do interior da Bahia.

Porque o ser sertanejo vai além do trivial. Ele se representa em cada letra do cordel, em cada causo ou expressão. No concretizar de um sonho, muitas vezes insólito, do poeta que quer ver o seu folheto impresso, e mais: o seu cordel lido. Uma motivação que parece vir de outros mundos, com a ousada intenção de fazer desse uma mesclagem do sem limites. A marginalidade híbrida de se ser o que é: o sertão in presso.

\section{REFERÊNCIAS}

CALVINO, Ítalo. La machine littérature. Paris: Seuil, 1984.

CASCUDO, Câmara. Vaqueiros e cantadores: folclore poetí co do sertão de Pernambuco, Paraíba, Rio Grande do Norte e Ceará . Rio de Janeiro: Tecnoprint/Edições de Ouro, 1968.

CHIAMPI, Irlermar. O realismo maravilhoso: forma e ideologia no romance hispano- americano. São Paulo: Perspectiva, 1980.

CESERANI, Remo. O fantástico. Trad. Nilton Cezar Tridapalli. Curitiba: Ed. UFPR, 2006.

DIÉGUES Júnior, Manuel. A literatura de cordel. In: BATISTA, Sebastião Nunes.

Antologia da literatura de cordel. FNatal: undação Jose Augusto, 1977. GARCÍA,

Flávio. (Org.). A banalização do insólito: questões de gênero literbrio

- mecanismos de construção narrativa. Rio de Janeiro: Dialogarts, 2007.

HAURÉLIO, Marco. Literatura de cordel: do sertão à sala de aula. São Paulo: Paulus, 2013. 
HAURÉLIO, Marco. Antologia do cordel brasileiro. São Paulo: Global, 2012.

MAXADO, Franklin. A lenda da lara é a mesma de lemanjá e das sereias. [S. I.: s. n., s. d.]. 9 p.

MAXADO, Franklin. Cordel. São Paulo: Hedra, 2007.

MAXADO, Franklin. Maxado Nordestino e o cordel em Feira de Santana. Re- vista Légua \& Meia: Revista de Literatura e Diversidade Cultural, v. 4, n. 3., p. 231-247, 2005. Disponível em: <http://leguaemeia.uefs.br/3/3_231-

254_cordel.pdf>. Acesso em: 10 jan. 2014.

MAXADO, Franklin. O casamento do lobisomem com uma vampira feiticeira. [S. I.: s. n., s. d.]. 9 p.

MAXADO, Franklin. O que é cordel. Mossoró: Editora Queima-Bucha, 2011.

MAXADO, Franklin. $O$ santo jumento no reino dos céus. [S. I.: s. n., s. d.]. 9 p.

MAXADO, Franklin. Saci e Bicho Folharaz no reino da bicharada. São Paulo: Luzeiro, 2011. 16 p.

MEDEIROS, Sérgio. Politeísmo literário. Dossiê Estudos culturais, Cult, n. 17, dez. 1998.

OLIVEIRA, Nelson. O cordel agora é wireless. Revista Lupa, ano 4, n. 6, 2009.

PITKIN, Hanna Fenichel. Representação: palavras, instituições e ideias. São Paulo: Lua Nova, 2006.

TODOROV, Tzvetan. As estruturas narrativas. Trad. Leyla Perrone-Moisés. 4. ed. São Paulo: Perspectiva, 2006, p. 147-166. Col. Debates 14.

TODOROV, Tzvetan. Introdução à literatura fantástica. Trad. Maria Clara Cor- rea Castello. 2. ed. São Paulo: Perspectiva, 1992. Col. Debates 98. 